\title{
The Effects of Using Direct Instruction Curricula in the Home to Teach Reading Comprehension to a 12-Year-Old Student with Cerebral Palsy
}

\author{
Anna Owens, Amy Violette, Kimberly P. Weber and T.F. McLaughlin*
}

Department of Special Education, Gonzaga University, USA

\begin{abstract}
The purpose of this study was to evaluate the effects of Direct Instruction curricula for teaching reading comprehension skills in the home. The participant was a 12-year-old girl who was enrolled in the seventh grade at a public middle school in the Pacific Northwest. She had been unable to pass her Washington Assessment of Student Learning (WASL) in the sixth grade. Two undergraduate students served as instructors. Each session began by asking 12 systematically random comprehension questions from the lessons of Corrective Reading Comprehension Skills Book B1. These comprehension questions served as the major dependent variable. The results indicated an increase number of correct reading comprehensions when Direct Instruction materials and procedures were employed. The use of Direct Instruction was cost effective, required little training to correctly implement, and was time efficient. The participant enjoyed the procedures and was proud of her improvements in reading.
\end{abstract}

Reading comprehension may be considered one of the most vital skills for successful academic performance in our schools and later in society [1]. Reading is required in most academic subjects and plays an indispensable role in success in school [2]. High levels of achievement in literacy are important for learning across the curriculum, for independence in engaging with print, for personal satisfaction, and reading sets the occasion for success in an increasingly informationbased economy [3]. Comprehension skills also play a critical role in mastering text. This takes place both inside and outside the classroom [4-7].

When No Child Left Behind was signed into law in 2002, the testing movement received additional emphasis at the federal level. This legislation made a student's ability to read and understand text paramount. This is especially true when test scores become the way we judge schools and school districts. This is important in spite of the fact that high stakes testing is not the best way to assess individual children and schools [8]. An unfortunate consequence of having insufficient comprehension skills is poor achievement in most of subjects-matter areas in the common schools $[4,9]$. Students overall academic success can be compromised by the lack of well-developed reading and literacy skills [5]. These challenges are often obvious in the middle school years. This is especially true when the teacher's role shifts to specialized subject matter instructor in math, history, language arts, and the sciences. The assumption that comprehension is mastered occurs at the middle school level and as a result [4]. Often, teachers rely on students' ability to read for meaning and understanding, and they assume that students will use textbooks to assist them in learning course content [10]. This assumption may well prevent necessary intervention from

\footnotetext{
*Address correspondence to this author at the Department of Special Education, Gonzaga University, 502 East Boone Avenue, Spokane, WA 992580102, USA; Tel: +509 313 3508; Fax: 509313 5965;

E-mail: tim.mclaughlin6@comcast.net,mclaughlin@gonzaga.edu
}

taking place which in turn promotes further difficulties in academic performance.

Because the root of many academic problems can be linked to a lack of reading comprehension, it is imperative that teachers recognize and consider the improving comprehension. This is especially true if they are contemplating other interventions such teaching reading in the content areas $[4-7,11]$. Generally, by the intermediate, middle, and secondary grades, the source for low performance in reading has been associated with low vocabulary and poor comprehension skills. The major observable manifestation of students' poor reading performance is inadequate comprehension while reading silently [11]. Despite this, silent reading is a common practice within schools. This in turn promotes a lack of student understanding in the various content areas taught in the middle school. Most middle school, instruction focuses on acquisition and proficiency of subject-matter areas rather than acquisition and proficiency in reading. Students are now expected to read to learn rather than to learn to read [12]. Acquisition of effective comprehension skills among students should reduce these challenges across content and promote academic success.

Knowing the difficulties that can arise from poor comprehension skills, it is critical that effective intervention takes place to develop and promote mastery of these skills [7]. Direct Instruction is one intervention strategy that can be utilized to promote reading comprehension [13]. This instructional technique is a form of focused instruction, which fosters rapid and reliable achievement in students regardless of ethnicity, "race," family background, or socioeconomic status [14]. Many of the procedures associated with Direct Instruction such as: (a) model, lead, and test error correction: (b) explicit instruction; (c) systematic review; (d) teaching only behaviors required in later learning of complex skills; (e) providing extra drill and practice, (f) the use of systematic feedback; and scripted lesson plants have a very robust research base [13]. After using Direct Instruction, teachers 
and other care providers have found large improvements in content areas such as math and reading $[13,15]$.

Direct Instruction can promote positive changes not only specific to the content studied but to other aspects of students' lives. For example, students who have received Direct Instruction generally outperform children taught with other forms of instruction in both academic and measures of selfesteem [13, 16, 17]. As these students become older, they have continued to outperform students who received traditional instruction. The Direct Instruction students have higher rates of high school completion as well as acceptance into college [18]. Over the years, Direct Instruction has been shown to be a successful teaching strategy for most children at risk for school failure $[13,19]$.

The purpose of this study was to examine the effects of a Direct Instruction reading curriculum on reading comprehension of a 12-year-old girl in middle school with difficulty in reading. Another purpose was to replicate our previous in home research [20] which found that using Direct Instruction materials could be effective with a typically developing preschool child.

\section{METHOD}

\section{Participant and Setting}

The participant was a 12-year-old girl enrolled in the seventh grade. She had been diagnosed with cerebral palsy and had been enrolled in general education classes at her middle school. She had attended special education in her elementary schooling. She received services in a resource room program at her local elementary school. She had been unable to pass the Washington Assessment of Student Learning (WASL) since she began taking the test in the fourth grade. At the time of this study, she was placed in the general education classes in her neighborhood middle school. She had maintained a 3.8 grade point average. However, she was not able to perform well enough on the WASL to pass in the area of reading comprehension. Her parents felt grade point average was high because she never had a late assignment, completed all of her work accurately, and was very pleasant to her teachers and other students. In addition, she was also very diligent about completing her homework as soon as she got home each night after school.

An area of concern voiced by participant's parents was the amount of time the participant took to complete her homework. On average it took between three and four hours a night for her to complete her assignments. Her parents also recognized that there was a large need to strengthen the child's reading fluency and comprehension skills. It was felt that this would help her succeed in other subject areas. A second area of concern was the level of frustration the participant sometimes displayed as she continued to work hard, succeed in her classroom, but still failed the Washington Assessment of Student Learning (WASL). Scoring high on the WASL was typically mentioned each day in the participant's classes as a means to motivate the students to try harder in their studies so they might pass the next WASL series. According to her mother, a result of this daily pressure was a decline in her child's self-esteem.

The setting was the participant's home in Spokane Valley, WA. The sessions took place primarily after school be- tween 4:00 to 4:45 p.m. On the weekends, two sessions were held each day (one in the mid-morning and one in the midafternoon). Data collection and reading instruction were carried out by the first two authors. Both were also completing their course requirements at a local private university [21]. The only other individual involved in the home was the participant's father. He served as an observer for interobserver agreement when the second author was not available due to the university holidays.

\section{Dependent Variable: Answering Reading Comprehen- sion Questions}

The number of correct comprehension questions was the dependent variable. The 12-question pretests focused on three areas of reading comprehension (deduction, inference, and definitions). The participant received no feedback regarding her performance on each pretest. These 12 questions were further divided into sub-questions. The participant also needed to get each sub question correct to be able to count the question as correct. For each session, the first two authors recorded the participant's oral answers next to the pre-printed correct answer in the teacher's edition of the curriculum.

\section{Materials}

The pre-test items were constructed using the questions directly from the Direct Instruction Curricula, SRA Corrective Reading Comprehension Skills Book B1 [22]. There were five inference, five deduction, and five vocabulary questions. These questions were placed three different sets: Set 1 , Set 2, and Set 3. Forty-five total questions were asked over the duration of 18 pretests. Each pretest also had four systematically random questions from each of the three lesson sets.

The Direct Instruction materials included the scripted lessons 2-22 from the SRA Corrective Reading Comprehension Skills Teacher Presentation Book B1. The workbook pages for lessons 2-22 were copied from the corresponding student workbook pages. Other materials needed were a small white board, dry erase markers, and eraser. For example, Lesson 4, Exercise 7, required the instructor to draw horizontal, vertical, and slanted lines on a board for the student. The instructor then said, "I'll point to each line. You tell me if the line is horizontal, slanted, or vertical." Finally, a binder for each lesson's completed pretest and workbook pages was used to keep track of student work.

\section{Home Based Reward System}

The participant was told at the beginning of the study that if she worked hard, she participant could earn various items. Different dollar amounts were also used so she could take part in a future basketball trip to the University of Arizona. This was an activity that would also include her two younger sisters. A free dish TV night coupons were also used. She was very excited about the mystery that surrounded the items. The sections for each worksheet were alphabetical, so the corresponding letters on the lesson would be placed in a bowl. The participant would select three letters. For each of the three letters selected, if the participant had scored $100 \%$ on she would earn a mystery prize listed on that slip of pa- 
per. These items were set up so she would never know which section would be graded for her mystery items. This system was in effect for both baseline and the Direct Instruction phases of the study.

\section{Experimental Design and Conditions}

A multiple baseline design [23] across question sets was used to evaluate the effects of Direct Instruction reading materials. This design allowed for a session by session evaluation of the efficacy of Direct Instruction to teach comprehension skills to our participant without having to remove the intervention and later reintroduce Direct Instruction procedures [23].

Baseline. During baseline, the first two authors gave a pretest to the participant. The pretest was given each session prior to the lesson of the day being taught. No feedback or error correction were provided. However, before the first pretest was administered, the researchers explained to the participant that it was normal that she would not know all of the answers to the questions. Each of the pre-tests employed different questions over different reading material. Baseline was in effect for 2 to 6 sessions.

Direct instruction. During Direct Instruction each of the 18 lessons were broken down into numerical exercises. These lessons were taught in isolation until the participant could answer the entire exercise correctly. For example, Lesson 7, Exercise 1, Deductions, followed these 5 steps: Step 1 the researcher said, "Here's a rule. Every muscle pulls. Say that rule." Researcher signaled for the student to respond. The participant responded, "Every muscle pulls." Step 2 Researcher said, "Listen. Every muscle pulls. A biceps is a muscle. So..." Instructor signaled. Participant responded with researcher, "A bicep pulls." Step 3 the instructor said, "My turn to say the whole deduction. Every muscle pulls. A biceps is a muscle. So, a biceps pulls." Step 4 the instructor said, "Say the deduction with me. Get ready." Instructor signaled. Researcher and participant said, "Every muscle pulls. A biceps is a muscle. So a biceps pulls." The instructor repeated this step until the participant could say this without any errors. Step 5 the researcher said, "All by yourself. Say the whole deduction." The instructor signaled. The participant said, "Every muscle pulls. A biceps is a muscle. So, a biceps pulls." This step was also repeated until firm with the participant. This was the format for every exercise subset for each of the 22 lessons taught.

If the participant responded correctly no further instruction was required and the instructor could move on to the next exercise. If the participant responded incorrectly she was immediately corrected and then retested. If the participant responded incorrectly after error correction, she was retaught the whole exercise from the beginning until they were able to pass the test over all the material and move to the next lesson

After completing the entire lesson, the participant would then complete her workbook pages that were specific to the lesson taught. Some of the workbook pages required prompting from the first authors to ask questions or to have her write the answers. Later lessons required the participant to work independently. When the workbook pages were completed then researcher and the participant corrected them together. At this time any other errors were corrected and explained to the participant.

\section{Data Collection and Reliability}

Reliability of measurement was gathered from the written work for each session. Interobserver agreement was conducted on the first pre-test given, and there after every third session. The participant would answer each of the twelve pre-test questions and the researcher would record the answers. The first researcher would have a tally sheet numbered 1-12 and would place a check mark next to any number that corresponded to the question the participant had answered incorrectly. The second researcher would have a separate tally sheet numbered 1-12 and would score the questions independently of the first researcher. After completing the tally sheets the researchers compared their scoring. The percent of interobserver agreement was figured by using the following formula: agreements/agreements + disagreements $=$ of interobserver agreement was $100 \%$. $\mathrm{x}$ 100. The percent

\section{RESULTS}

The results of the number of correct responses the participant answered are shown in Fig. (1). During Baseline for Set 1, the participant's average number of comprehension questions answered correctly was 2.5 (range 2-3 correct answers). For Direct Instruction in Set 1, the participant's average number of correct comprehension questions answered correctly increased to 4.0 with a range $3-4$.

During baseline for Set 2, the participant's average number of questions answered correctly was low $(M=1$; range 0-3). When Direct Instruction was employed for Set 2, the participant's average number of questions answered correctly increased to an average of 3.1 (range 1-4 correct answers). During baseline for Set 3, the mean number of comprehension questions answered correctly was 0.8 with a range of 0-3. For the Direct Instruction for Set 3, number of questions answered correctly increased to 2.5 with a range of from 1-4.

\section{DISCUSSION}

The Direct Instruction curriculum that was used in this research study was shown to be an effective curriculum intervention to help increase the participant's reading comprehension. Also during the Direct Instruction phases of the case report, the participant seemed to truly enjoy her sessions, continually asking when she would be able to view the chart to see her improvements. According to her parents, she was clearly motivated by the mystery rewards, and really enjoyed receiving the rewards after her workbook pages were corrected and she had scored $100 \%$. The participant said at the end of the study, "this teaching style helps me feel better about myself, and I can't wait to try harder each time”.

An item we found of interest, was how much the participant's other siblings wanted to be a part of the study when 


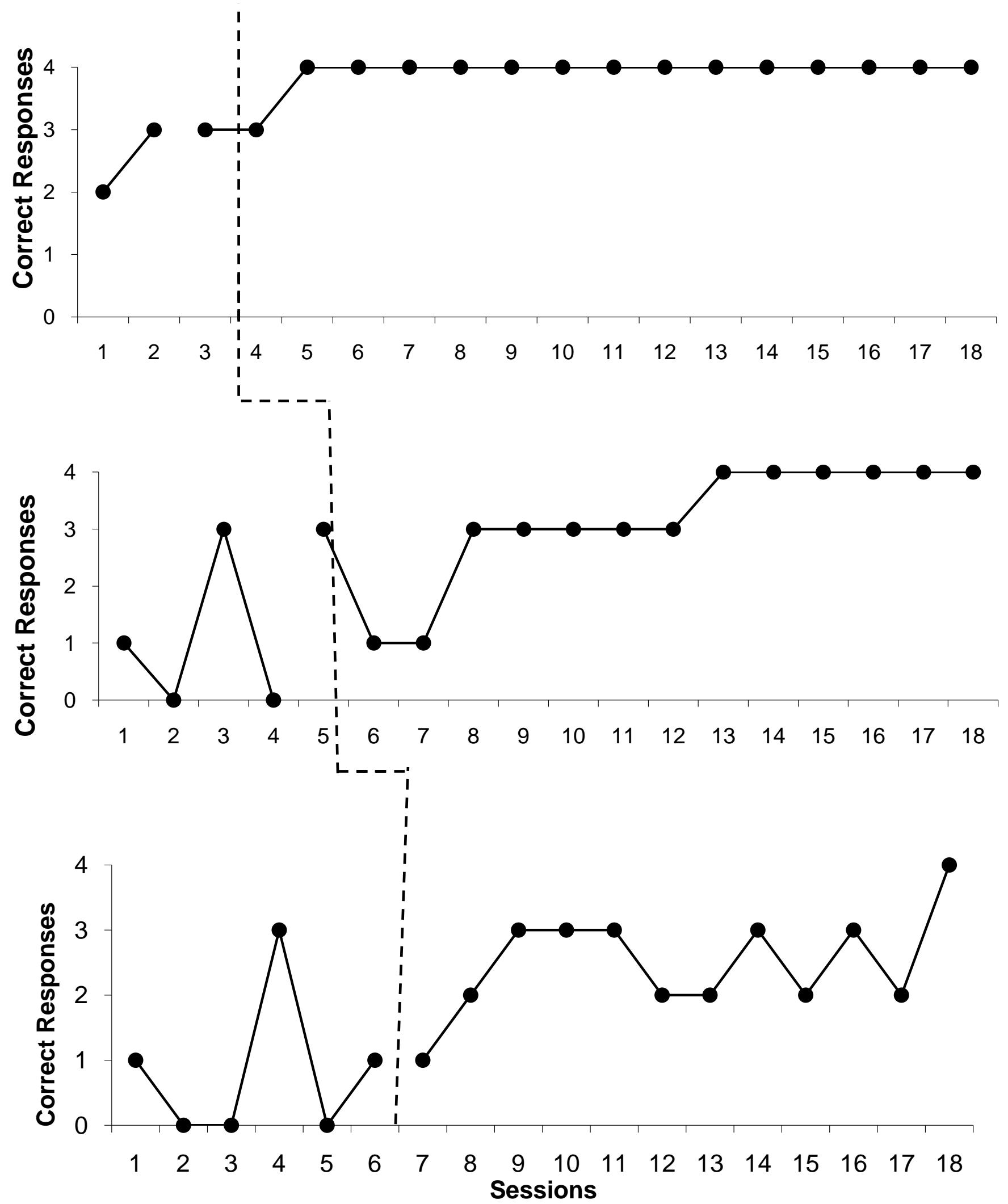

Fig. (1). The number of correct comprehension questions answered during each of the three Sets for baseline and Direct Instruction. 
they knew the participant could earn things for her efforts in reading. They made signs for the participant and cheered for her as she went through the different lessons. And each sibling wanted to know what the participant had learned for the day, at which point the participant would recite many of the definitions and other exercises that she had learned for the day. It was apparent that the participant's success was a positive experience for the participant as well as the other members of the family.

Alvermann [4] has urged middle schools should make teaching of reading skills a top priority. If reading comprehension is not going to be systematically taught, then home instruction maybe a method to assist students with low skills in this area. Systematic home instruction with evidencebased materials can do much to improve the reading skills of students $[14,20]$.

The present case report provides an additional replication regarding the use of Direct Instruction materials in the home. However, in the present report an older student was employed and a more complex skill was improved. It appears that Direct Instruction materials can be implemented by a wide variety of individuals ranging from parents [14] to high school general education students [24-26]. Also, the present research continues to add to the evidence base of Direct Instruction and its procedures across a wide variety of skills, settings, and populations [13, 27].

There were limitations to the present case report. First, one of the authors was the participant's mother. Second, it would have improved the strength of the outcomes if data on words read orally per minute could have been also gathered. Finally, it would have strengthened the efficacy of the intervention to have monitored her reading skills in the area of comprehension in the curricular materials employed in her middle school curricula. The home-based reward system was in effect for both baseline and intervention. However, the participant earned a larger number of rewards during the intervention than baseline. Therefore, the present outcomes are limited due to the change in the density of reinforcement that the participant did earn. In addition, the contribution of practice effects cannot be totally ruled out in the present investigation. Since only one child was involved, caution needs to be exercised when generalizing the present outcomes to a wider population [23]. The use of additional participants or a between groups design with a control group would do much to increase the generalizability of the present outcomes to a wider population. Finally, the effects of the additional attention that the participant received from her siblings may have contributed to the present outcomes. Additional research where the frequency of praise statements or encouragements are monitored would be an appropriate strategy to remove such a possible confound in the reported outcomes.

In conclusion the first author (the participant's mother) was very pleased with the results she plans to continue the program until the book was completed, and to continue to review the material in the hopes that generalization will take place to the participant's other subject areas. The participant's mother was one of the researchers and she felt that her daughter's success in reading comprehension assisted in the reduction of her stress regarding her daughter's education and overall wellbeing. The mother has pledged to find other
Direct Instruction curricula to assist the participant in her mathematics skills as well. Finally, the improvement in her reading and self-confidence has allowed the participant to successfully take part in a wide variety of after school activities.

\section{ACKNOWLEDGEMENTS}

This research was completed in partial fulfillment for the requirements of teacher certification and endorsement for special and elementary education in the Department of Special Education at Gonzaga University. The authors would like to thank the participant and family for allowing us to complete this study.

\section{REFERENCES}

[1] Livingstone DW. The education-jobs gap: underemployment or economic democracy. Boulder, Co: Westview Press 1998.

[2] Thomas G. Teaching and learning reading. Thrust Edu Lead 1996; 26: $32-7$

[3] Raphael TE, Au K. Enhancing comprehension and test taking across grades and content areas. Read Teach 2005; 59: 206-22.

[4] Alvermann DE. Effective literacy instruction for adolescents. J Lithotr Res 2002; 34; 189-208.

[5] Alvermann DE, Phelps S. Content reading and literacy: succeeding in today's diverse classrooms. $3^{\text {rd }}$ ed. Boston: Allyn and Bacon 2002.

[6] Greenwood CA, Hart B, Walker D, Risley TR. The opportunity to respond and academic performance revisited: a behavioral theory of developmental retardation and its prevention. In: Gardner III R, Sainato D, Cooper JO, et al., Eds. Behavior analysis in education: focus on measurably superior instruction. Pacific Grove, CA: Brooks/Cole 1994; pp. 213-23

[7] Osborn J, Lehr F, Eds. Literacy for all: issues in teaching and learning. New York: Guilford 1998.

[8] Paris SG. Why learner-centered assessment is better than highstakes testing. In: Lambert NM, McCombs BL, Eds. How students learn: reforming schools through learner-centered education. Washington, DC: American Psychological Association 1998; pp 189209.

[9] Berliner DC, Biddle B. The manufactured crisis: myths, fraud, and the attack on America's schools. Basic Books, New York 2004.

[10] Kozen AA, Murray RK, Windell I. Increasing all students' chance to achieve: using and adapting anticipation guides with middle school learners. Int School Clin 2006; 41: 195-201.

[11] Rasinsky T, Padak N. Fluency beyond the primary grades: helping adolescent struggling readers. Voice Mid 2005; 13: 34-9.

[12] Chall JS. Two vocabularies for reading: recognition and meaning. In: McKeowen M, Curtis M, Eds. The nature of vocabulary acquisition. Hillsdale, NJ: Lawrence Erlbaum 1987; pp. 7-17.

[13] Boston MA. Introduction to direct instruction. Marchand-Martella NE, Slocum TA, Martella R, Eds. Pearson Education Inc 2004.

[14] Vacha EF, McLaughlin TF. The social structural, family, school, and personal characteristics of at-risk students: policy recommendations for school personnel. J Edu 1992; 174(3): 9-25.

[15] Gersten R, Keating T, Becker WC. The continued impact of the direct instruction model: longitudinal studies of follow through students. Edu and Treat Child 1988; 11: 318-27.

[16] Adams GL, Engelmann S. Research on direct instruction: 25 years beyond DISTAR. Seattle, WA: Educational Achievement Systems 1996.

[17] Darch C, Gersten R, Taylor R. Evaluation of Williamsburg County direct instruction program: factors leading to success in rural elementary programs. Res Rural Edu 1987; 4: 111-8.

[18] Gersten R, Keating T. Long term benefits from direct instruction. Edu Lead 87; 44(6): 28-31.

[19] Gersten R, Carnine D, Woodward J. Direct instruction research: the third decade. Rem Sp Edu 1987; 8(6): 48-56.

[20] Stenseth S, McLaughlin TF. The effects of contingent consequences with direct instruction reading with a preschool child in the home. J of Prec Teach Cel 1996; 13(2): 53-6. 
[21] McLaughlin TF, Williams BF, Williams RL, et al. Behavioral training for teachers in special education: the Gonzaga University program. Behav Interv 1999; 14: 83-134.

[22] Engelmann S, Osborn S, Hanner S. SRA corrective reading comprehension skills book B1 Chicago: SRA Associates 1988.

[23] Kazdin AE. Single case research designs: methods for clinical and applied settings. New York: Oxford University Press 1982.

[24] Blackwell A, Stookey S, McLaughlin TF. The effects of using direct instruction and a re-reading contingency with precision teaching. J Prec Teach and Cel 1996; 13(2): 19-22.
[25] Holz KR, Peck S M, McLaughlin TF, Stookey S. The effects of using direct instruction reading and a re-reading contingency coupled with a reward and praise reading and a re-reading contingency coupled with a reward and praise. J Prec Teach Cel 1997; 14(1): 35-40.

[26] Gregory A, McLaughlin TF, Weber KP, Stookey S. The effects of using direct instruction and a re-reading contingency with a high school student. Int J Spec Edu 2005: 20(1): 50-4.

[27] Glang A, Ylvisaker M, Stein M, Ehlhardt L, Todis B, Tyler J. Validated instructional practices: application to students with traumatic brain injury. J Head Trauma Rehabil 2008; 23: 243-51.

Received: December 17, 2008

Revised: January 13, 2009

Accepted: January 14, 2009

(c) Allegaert et al.; Licensee Bentham Open.

This is an open access article licensed under the terms of the Creative Commons Attribution Non-Commercial License (http://creativecommons.org/licenses/bync/3.0/) which permits unrestricted, non-commercial use, distribution and reproduction in any medium, provided the work is properly cited. 